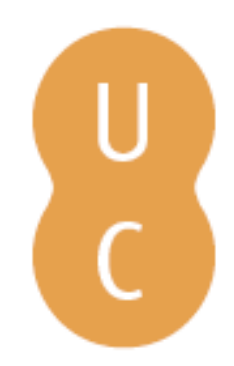

\title{
nombalina
}

\section{El mito de Orfeo en el teatro argentino contemporáneo: la casa sin sosiego de Griselda Gambaro}

\author{
Autor(es): Galan, Lía \\ Publicado por: Imprensa da Universidade de Coimbra \\ URL \\ persistente: URI:http://hdl.handle.net/10316.2/43003 \\ DOI: $\quad$ DOI:https://doi.org/10.14195/978-989-26-1439-7_23 \\ Accessed : $\quad$ 26-Apr-2023 16:24:45
}

A navegação consulta e descarregamento dos títulos inseridos nas Bibliotecas Digitais UC Digitalis, UC Pombalina e UC Impactum, pressupõem a aceitação plena e sem reservas dos Termos e Condições de Uso destas Bibliotecas Digitais, disponíveis em https://digitalis.uc.pt/pt-pt/termos.

Conforme exposto nos referidos Termos e Condições de Uso, o descarregamento de títulos de acesso restrito requer uma licença válida de autorização devendo o utilizador aceder ao(s) documento(s) a partir de um endereço de IP da instituição detentora da supramencionada licença.

Ao utilizador é apenas permitido o descarregamento para uso pessoal, pelo que o emprego do(s) título(s) descarregado(s) para outro fim, designadamente comercial, carece de autorização do respetivo autor ou editor da obra.

Na medida em que todas as obras da UC Digitalis se encontram protegidas pelo Código do Direito de Autor e Direitos Conexos e demais legislação aplicável, toda a cópia, parcial ou total, deste documento, nos casos em que é legalmente admitida, deverá conter ou fazer-se acompanhar por este aviso.

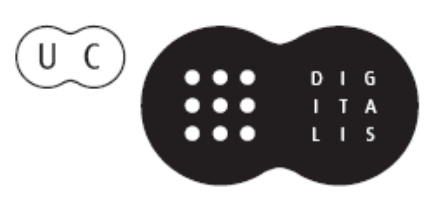




\section{Pervivencia del mundo clásico en la literatura:}

\section{tradición y relecturas}

\section{Aldo Rubén Pricco, Stella Maris Moro (coords.)}

IMPRENSA DA UNIVERSIDADE DE COIMBRA 


\title{
El mito de Orfeo en el teAtro argentino Contemporáneo: La CASA SIN SOSIEGO DE Griselda Gambaro \\ (The myth of Orpheus in contemporary Argentine theatre: La casa sin sosiego by Griselda Gambaro)
}

\author{
Lía Galan (ligal43@yahoo.com.ar) \\ Centro de Estudios Latinos - Universidad Nacional de La Plata
}

\begin{abstract}
Resumen — La casa sin sosiego, escrita por G. Gambaro en 1991, es un drama escénico para ópera de cámara con música de Gerardo Gandini, creado por pedido de la Fundación Instituto Torcuato Di Tella y producido por el Centro de Experimentación en Ópera y Ballet del Teatro Colón de Buenos Aires. La casa sin sosiego es una reelaboración del mito de Orfeo en el contexto de la post-dictadura argentina y la búsqueda de personas desaparecidas durante el gobierno militar en Argentina (1976-1983). Muestra las relaciones intertextuales variadas que hacen referencia, de manera implícita, a Ovidio (Metamorfosis, 10. 1-85) y Virgilio (Geórgicas 4. 454-550) y, explícitamente, a La Favola d'Orfeo (ópera de Monteverdi), que aparece como un leit-motive de la obra, y el soneto IX de Sonetos a Orfeo de Rilke. En la obra de Gambaro, Juan, el nuevo Orfeo, está en busca de su esposa Teresa (Eurídice), que se encuentra entre los muertos. La angustia de la pérdida le lleva a la breve reunión con su esposa en el Infierno, y de él sale con la dolorosa certeza de la mujer irrecuperable. Escrita años después de los acontecimientos, la pieza es una sutil llamada a la memoria de un pasado que no debe repetirse.
\end{abstract}

Palabras Clave: Gambaro, Orfeo, mito, ópera.

Abstract - La casa sin sosiego (The house without calm), written by G. Gambaro in 1991, is a scenic drama for chamber opera, with music by Gerardo Gandini, created by request of the Instituto Torcuato Di Tella Foundation and produced by the Center for Experimentation in Opera and Ballet of the Teatro Colon in Buenos Aires. La casa sin sosiego is a remaking of the myth of Orpheus in the context of the Argentine post-dictatorship and the search for missing persons during the military government in Argentina (1976-1983). It shows varied intertextual relations that refer, implicitly, to Ovid (Metamorphoses, 10. 1-85) and Virgilio (Georgics 4. 454-550), and explicitly, to La Favola d'Orfeo (Monteverdi's opera), which appears as a leit-motive of the play, and the sonnet IX of Sonnets to Orpheus of Rilke. In Gambaro's play, Juan, the new Orpheus, is looking for his wife Teresa (Eurydice), who is among the dead (persons). The anguish of loss leads him to the brief meeting with his wife in hell, from where he comes out with the painful certainty of the unrecoverable woman. Written years after the events, the piece is a subtle Gambaro's call to the memory of a past that must not be repeated. KeYwords: Gambaro, Orpheus, myth, opera.

Si los mitos, además de contar un cuento, entrañan en lo profundo misterios que se traducen en figuras y relatos, y cautivan a los lectores por sus múltiples 
sugerencias, el de Orfeo está entre los mitos más proteicos y atractivos desde la Antigüedad hasta nuestros días. Es quien desciende al Hades y regresa, algo reservado para muy pocos personajes míticos y que le confiere su singular condición mistérica.

Originariamente el mito de Orfeo tenía dos vertientes enlazadas. Es el músico paradigmático cuyo canto, acompañado de instrumentos, hechiza la naturaleza y detiene el tiempo. Es también el protagonista de una de las historias de amor más referidas y reelaboradas a lo largo de los siglos. En las bodas o en un paseo, una serpiente muerde a Eurídice que muere; el desconsolado esposo se interna en el Hades en busca de Plutón y Proserpina, para rogarles que le devuelvan a su esposa. Logra persuadirlos con su canto y Proserpina acepta el ruego, imponiendo como condición que Orfeo conduzca a su esposa sin volver la mirada, so pena de volver a perderla. Orfeo no cumple y pierde por segunda vez a Eurídice. Esta última es la sección de la fábula que casi exclusivamente ha pervivido en el imaginario posterior, especialmente a partir del Renacimiento. No obstante, el relato continúa con el largo dolor de Orfeo, su imposibilidad de regresar nuevamente al Hades y su apartamiento en las montañas, donde es atrapado y despedazado por las Ménades, y su cabeza es rescatada por Dionisos y depositada en su santuario como centro oracular ${ }^{1}$.

El paradigmático cantor tracio es la figura tutelar de los misterios órficos, una cosmovisión que afirma la pervivencia del alma humana en el trasmundo y se constituye en escuela para quienes adoptan el bios orphikós, con su correspondiente doctrina y grados que se escalonan en ritos e iniciaciones. Enlazado con manifestaciones análogas como el pitagorismo, el platonismo y neoplatonismo y reapareciendo en el cristianismo, el orfismo es una corriente de pensamiento subterráneo que influye en toda la cultura posterior.

Al respecto, Grimal afirma:

(Orfeo) es uno de los más oscuros y más cargados de simbolismo de cuantos registra la mitología helénica. Conocido desde época muy remota, ha evolucionado hasta convertirse en una verdadera teología, en torno a la cual existía una literatura muy abundante y, en gran medida, esotérica. No se puede decir que el mito de Orfeo no haya ejercido una influencia cierta en la formación del cristianismo primitivo y está atestiguado en la iconografía cristiana $^{2}$.

${ }^{1}$ De la muerte de Orfeo se relatan diversas versiones. Cf. Ovidio, Met., 11.1 y ss; Apolodoro, Biblioteca mitológica 1. 9. 25; Higino, Fábulas 14. 27, 14. 32; Higino, Astronomica 7. 3; Platón, El banquete 179d; Pausanias, Descripción de Grecia 9. 30. 5-6.

${ }^{2}$ Grimal 1989. 
El interés por este aspecto del mito tuvo un nuevo y vigoroso impulso a partir del descubrimiento de las laminillas de oro órficas ${ }^{3}$, objeto de múltiples estudios desde la aparición de la primera de ellas en Petelia, Calabria, en 1836. Se trata de un conjunto de textos religiosos escritos en pequeñas laminillas de oro que eran portados por el adepto órfico para que le sirviesen de guía y protección en los avatares de su viaje ultramundano.

Al igual que los chamanes, Orfeo es sanador y músico; encanta y domina a los animales salvajes, desciende a los infiernos para rescatar a Eurídice; su cabeza cortada se conserva luego y sirve de oráculo, al igual que todavía en el siglo XIX se hacía con los cráneos de los chamanes yukagires ${ }^{4}$.

Los textos más conocidos de la Antigüedad son el pasaje de las Geórgicas de Virgilio, 4. 454-550 y Metamorfosis de Ovidio, 10. 1-84, en los que se desarrolla con mayor amplitud el mito. El amor de Orfeo por Eurídice se convierte en fábula popular de todos los tiempos para expresar el amor que desafía a la muerte. Desde la ópera de Monteverdi al texto que nos ocupa, Orfeo encarna el poder del amor que no acepta la separación producida por la muerte y fielmente busca a la amada, perdida por segunda vez por un error o por una transgresión de las leyes naturales. Como se ha dicho, esta historia ofrece profundos simbolismos que ilustran la doctrina órfica pero no por tomarse en un sentido inmediato pierde su significación fundamental: la búsqueda de la amada que no se detiene ante las puertas de Hades, en donde es necesario perder toda esperanza.

Griselda Gambaro ofrece una nueva versión llevada al contexto de la pos dictadura. La casa sin sosiego fue escrita en 1991 y estrenada en junio de 1992 en la Sala Casacuberta del Teatro Municipal San Martín, como libreto para ópera de cámara, con música de Gerardo Gandini.

En la Antigüedad se produce el paso del mito primordial al "mito literario" de Orfeo y Eurídice en la obra de Virgilio, Geórgicas, logrando que la obra artística adquiriera una calidad tal que, a partir de entonces, ha sido considerada referente canónico del mito. El "mito literario", caracterizado por ser creación de un determinado autor, da lugar a una tradición y adopta plurivocidad ${ }^{5}$. Así, pues, el mito de Orfeo contado por Virgilio se convierte en versión canónica y es ésta la que más ha influido en la posteridad'.

${ }^{3}$ Sobre las laminillas órficas vide los estudios más recientes de Burkert 1975, Cole 1980, Calame 1995, Giangrande 1995, Tortorelli 1995a y b, Riedweg 1996, Merkelbach 1999, Bernabé - Jiménez 2001, Edmonds 2004. Sobre los aspectos arqueológicos de los hallazgos vide Bottini 1992.

${ }^{4}$ Cf. Eliade 1999: II. 219.

${ }^{5}$ González Delgado 2008: 21-22.

${ }^{6}$ Son incontables las reelaboraciones y versiones a lo largo del tiempo y del espacio. Algunos ejemplos argentinos contemporáneos son Los tangos de Orfeo (1965) de A. Rodríguez Muñoz, Orfeo en las tinieblas (1965) de R. N. Medina, el drama Latin American Trip (1978) de A. Calveyra. 
Uno de los motivos que se repite a lo largo de las escenas contiene los versos de Dante (Div. Com. III. 9). Esto ubica desde el comienzo la naturaleza y las características del drama, versos que retoma Monteverdi en su ópera y cita Gambaro, y que también son utilizados en el informe de la Conadep Nunca más para referirse a los centros clandestinos de detención y tortura. Se crea una sutil asociación que el desarrollo de la obra irá confirmando. Pocos elementos ubican la obra en la Argentina contemporánea. Esta mínima presencia de referencias precisas pero subterráneas permite relacionar los sucesos con un tiempo especial de Argentina.

Es posible, además, identificar algunas características de la tragedia griega. Hay una peripecia inicial ya que Juan vuelve del mar a reunirse con su amada esposa, esperando encontrar sosiego y felicidad ${ }^{7}$. Al llegar, le muestran a Teresa muerta y esto constituye la peripecia de apertura al pasar Juan de la felicidad por el reencuentro a la pérdida por la muerte. En el final se produce el reconocimiento (anagnórisis) y, como en Eurípides, Juan y Teresa aparecen como seres sometidos a un doloroso destino que no comprenden, por causas que no atinan a entender. Se representa así la búsqueda que cumplen familiares de los desaparecidos de la dictadura militar impulsada por la angustia y el imperativo de recobrar la identidad de muertos sin nombre y reclamar castigo para los culpables.

La obra de Gambaro hace explícitos los textos gestores de su versión. Como lo afirmara Barthes ${ }^{8}$, un texto es reescritura de otros textos y la cadena se desliza a lo largo del tiempo, de modo tal que una referencia a Monteverdi, Dante o Rilke entraña una extensa corriente, a veces laberíntica, de transmisión. Entre el Humanismo y el Renacimiento se reponen versiones del mito consolidadas por los poetas romanos y, como se ha dicho, el mito literario de Orfeo contado por Virgilio se convierte en versión canónica9.
“Qué locura a mí, desdichada”, aquella dice, "y a ti te perdió, Orfeo?
¿Qué gran locura? He aquí que de nuevo hacia atrás, crueles los hados me llaman y el sueño cierra mis ojos desfallecidos.
Y ahora, adiós: envuelta en una inmensa noche me siento arrastrada y hacia ti tiendo, sin ser ya tuya jay! mis manos sin fuerza ${ }^{10}$. (Geórgica 4. 495-498)

\footnotetext{
7 "Teresa me abrazó cuando partí, y nos besamos, / y sus dientes eran frescos, como su lengua. Me dijo 'hasta pronto", Escena 1.

${ }^{8}$ Cf. Barthes 1993: 76.

${ }^{9}$ A partir de la versión virgiliana, Ovidio retoma la historia en Metamorfosis 10. 1-84 y 11.1.

${ }_{10}$ illa "quis et me», inquit, "miseram et te perdidil, Orpheu? /Quis tantus furor? En iterum crudelia retro /Fata vocant, conditque natantia lumina somnus./ Iamque vale: feror ingenti circumdata nocte, / invalidasque tibi tendens, heu! non tua, palmas!
} 
Los versos concentran la angustia de Eurídice, sumergida nueva y definitivamente en las sombras del Hades.

La casa sin sosiego ha sido concebida con la apoyatura de textos y es manifiesto el interés por hacer explícita la relación en la que la representación adquiere su más profundo significado. Las más importantes y desarrolladas se refieren directamente a Orfeo: La fábula de Orfeo, de Monteverdi, y los Sonetos de Orfeo, de Rilke. Hay, además, explícitas aunque breves referencias a textos que no se vinculan con el mito pero que extienden el horizonte hermenéutico aportando nuevas imágenes para su más completa intelección.

La obra está compuesta por una introducción, cinco interludios y seis escenas: 1) La muerte, 2) El bar, 3) El loquero, 4) La antesala, 5) $\mathrm{E}$ infierno, 6) El regreso. Los interludios están a cargo de la protagonista, Teresa, una versión de Eurídice; Juan, su esposo, es Orfeo en su ciega búsqueda de la esposa desaparecida.

Liminar e introductoria es la cita de Dante (Div. Com. III. 9) que aparece en la ópera de Monteverdi para señalar la entrada de Orfeo en el Infierno. La fábula de Orfeo (título original en italiano: La favola d'Orfeo) es una ópera compuesta por un prólogo y cinco actos con música de Claudio Monteverdi y libreto en italiano de Alessandro Striggio el Joven. Fue estrenada en la Accademia degl'Invaghiti en Mantua (1607). Ya en el libreto de Ottavio Rinuccini para la obra de Jacopo Peri, Euridice (1600), que seguramente influyó en Striggio, se había modificado el desenlace pues la audiencia reclamaba un final feliz, algo que también ocurre en el libreto de Striggio según el cual Orfeo recupera finalmente a Eurídice ${ }^{11}$. Sin embargo, pese a la explícita referencia a la ópera de Monteverdi, el texto de Gambaro se conserva la versión virgiliana por cuanto Juan/Orfeo pierde definitivamente a Teresa/Eurídice y sólo queda el dolor de la memoria. En el acto tercero de la ópera italiana aparece la cita liminar con la que comienza $L a$ casa sin sosiego. Orfeo llega a la laguna Estigia en compañía de la Esperanza, quien le anuncia que no puede llevarlo más allá porque está grabada en la piedra la advertencia de Dante en las puertas del Infierno: «Abandonad toda esperanza los que entráis» («Lasciate ogni speranza / Voi ch'entrate»). Caronte se niega a llevarlo en su barca pero Orfeo lo hace dormir con su música, roba la barca y accede al Hades. Mientras tanto, un coro de espíritus infernales celebra al Hombre, criatura que no intenta ninguna empresa en vano y contra quien la Naturaleza no sabe armarse.

Las siguientes citas remiten, de manera directa, a los poemas de Elsa Morante, reunidos en El Mundo salvado por los niños ${ }^{12}$ : "Memoria, memoria, casa

\footnotetext{
${ }^{11}$ Cf. Sternfeld 1986: 20-45.

${ }^{12}$ Se citan pasajes del poema La sera domenicale (La noche dominical) incluido en Il mondo salvato dai ragazzini e altri poemi (El mundo salvado por los niños y otros poemas), de 1968.
} 
de pena" (passim) y "Eli, Eli, sin respuesta” (passim). Esta última remite a la conocida expresión agónica de Jesús en Mateo 27. 46 "Eli Eli ¿lama sabactani?" («Dios mío Dios mío ¿Porque me has abandonado?») por el dolor humano de la muerte inminente. La primera resume uno de los motivos fundamentales de la obra: la memoria de la pérdida y el dolor que encierra.

Las citas textuales le dan profundidad poética y filosófica a los sucesos escénicos que construyen una imagen de la realidad actual de la post-dictadura en un drama humano y brutal, concebido bajo la forma tradicional de descenso al Infierno. Juan y Teresa, de distinto modo, hacen el oscuro viaje. Teresa, como Eurídice, es la primera en enfrentar "el lugar de las tinieblas" y su lamento resuena en los cinco intermedios que escanden la obra con el canto de la voz femenina.

La Introducción es breve y contiene sólo los dos versos de Dante citados por Monteverdi a los que ya hemos hecho referencia con la sentencia a la entrada del Infierno. Estos versos reaparecen en la escena 4, momento en el cual Juan llega hasta el guardián que custodia la entrada del Infierno. La cita de Dante marca el tono de la obra: como Orfeo, Juan busca a su esposa y no se detiene hasta llegar al Infierno.

En la primera escena ("La Muerte"), Juan busca a Teresa y encuentra a Ruth quien le muestra una bolsa negra con un cadáver. Es Teresa que se ha ahogado. Juan destapa el cadáver y se encuentra con una mujer hinchada, desfigurada, alguien que no reconoce como Teresa. Mientras Ruth entre llantos trata de explicarle que se ha ahogado, Juan repite con insistencia "no es ella".

La escena, como después ocurrirá con otras, trae un breve fragmento de la ópera de Monteverdi. Teresa, como Eurídice, está muerta y así se expresa, confirmando el destino que Juan no acepta:

La tua diletta sposa

è morta

Hacia el final de la escena, las mujeres dicen el verso de Morante que se volverá a repetir en varios momentos de la obra: "Memoria, memoria, casa de pena".

En la segunda escena, Juan comienza su peregrinación buscando a su esposa, la verdadera Teresa, sin reconocer lo que le ha mostrado Ruth. En el Bar donde se desarrolla, los hombres cantan:

Se fue, se fue el verano

Dejó paso al otoño

Cuando se vaya el otoño

¿Quién sabrá lo que vendrá?

La referencia al otoño presenta la imagen de un tiempo crepuscular, declinante hacia la muerte de la naturaleza que traerá el invierno. Sería, sin 
duda, inadecuada la pregunta final del canto de qué vendrá tras el otoño si no se entiende como alusión a un tiempo determinado en el que se sitúan los sucesos. Puede encontrarse aquí una referencia al punto en torno al cual se comprende cuál es el encuadre de la tragedia: el golpe de Estado con el que comenzó la dictadura militar en 1976 ocurrió el 24 de marzo, apenas comenzado el otoño. En este contexto, la pregunta “Quién sabrá lo que vendrá?” abre un espacio oscuro e inquietante de presagios.

Juan explica que, cuando volvió, "faltaba Teresa”. Reaparece entonces el motivo de Monteverdi, que matiza y anticipa la verdad que Juan no acepta:

La tua bella Euridice

Ohi me che odo

La tua diletta aposa

È morta

Ohi me.

La escena 3 presenta el loquero, una especie de etapa previa en el avance hacia el Infierno. Son breves pero elocuentes los datos por los que el loquero puede asociarse con un centro de detención clandestina como los que existieron durante la última dictadura militar. Hay en la escena cuatro o cinco mujeres, una de las cuales parece Teresa. Repentinamente las mujeres se sienten alegres y esto parece obedecer al reconocimiento de Teresa a través de su vestido:

Mujeres (en un arranque, repentinamente alegres) - ¡Tiene su mismo vestido! Es un vestido ¡que nosotras le pusimos! La trajeron muda desnuda ¡Con marcas de cigarrillos!

La desnudez y las marcas de quemaduras de cigarrillo resumen el acto de tortura al que ha sido sometida Teresa.

En la escena 4, Juan ha llegado a la antesala del Infierno. El motivo poético-musical de los versos de Dante se contextualiza como no lo hacían en la Introducción.

Juan - Dicen...detrás de esta oficina hay mucha gente. Sin anotar. [...] Guardia - ... Pase, señor. Si usted dice que hay gente allí (señala a sus espaldas) será cierto. Pero atento, si entra, puede no salir.

Lasciate ogni speranza

Voi ch'entrate.

Guardia - Nadie puede ver en ese infierno, sin quedarse ciego o tuerto. También muerto. ¿Paga el precio? 
Definitivamente Juan se ha convertido en Orfeo, dispuesto a penetrar en el Infierno en busca de su esposa, a quien en la quinta escena finalmente encuentra:

Juan - ... Teresa, mirame. (Ella lo mira sin expresión) Volvamos a casa.

Teresa - Casa de pena.

Juan - No. (La levanta) Los rosales tienen rosas...

Teresa - Sueño de nadie bajo tantos párpados.

Es evidente la cita de Rilke, epitafio escrito por el propio poeta para su sepulcro: "Rosa, oh contradicción pura, deleite de ser el sueño de nadie bajo tantos párpados" ${ }^{13}$. No nos detendremos en las múltiples resonancias que ofrecen las citas de Rilke, en particular el poema 9 de los Sonetos de Orfeo (Sonette an Orpheus, 1923) del que presentamos una traducción:

Tan sólo aquel que levantó la lira, incluso entre las sombras, puede expresar, entre presentimientos, la alabanza infinita.

Tan sólo aquel que comió con los muertos la adormidera, la de ellos, no volverá a perder el más leve sonido.

Aunque el reflejo del estanque se desvanezca muchas veces:

sabe la imagen.

Sólo en el reino doble se volverán las voces eternas y suaves.

El soneto se inscribe en la escena final en la que Juan encuentra a Teresa en la cena de muertos que se celebra en el Infierno; reaparecen las citas de Dante / Monteverdi. Teresa está muerta.

Tu sè morta sè morta mia vita.

Juan tiene entonces la terrible evidencia de la muerte de Teresa en ese mundo donde se celebra la cena de los muertos. Estos muertos sin nombre habitan

\footnotetext{
${ }^{13}$ Rose, ob reiner Widerspruch, Lust, Niemandes Schlaf zu sein unter soviel Lidern.
} 
una casa de pena en la que los consume, como a Tántalo, el hambre y la sed. Es ésta la casa sin sosiego. El Guardia lo sustrae de la visión y lo obliga a salir:

Guardia - No se puede vivir en esa casa. (Divertido) Por eso olvidamos. ( $A$ Juan) Salga y olvide. (Lo empuja suavemente)

El horror de esta visión hace que se tensen dos respuestas contrarias: la recomendación del Guardián de olvidar para seguir viviendo y el doloroso ejercicio de la memoria que opera con sombras y pena.

La escena final trae el definitivo reconocimiento de Juan ("Es ella") en su casa como en la primera escena, cumplido el pasaje por el Infierno. E1 horror de la verdad enlaza la angustia de Juan con los cantos del interludio. Se acumulan las citas que se reiteran a lo largo de las escenas. Para Juan no puede ya haber olvido y son inútiles las advertencias del Guardián. El desgarrador imperativo de la memoria escande su viaje y se consagra en el desenlace.

Los breves interludios en la voz de Teresa abren una dimensión lírica que permite comprender la trayectoria de Juan como un viaje hacia el reino de la muerte. El no saber ni comprender de este nuevo Orfeo resuena en el no entender de Teresa, quien se percibe condenada, sumergida en un mundo de sombras, sin saber inicialmente dónde está ni porqué ha sido llevada allí. Esta situación se revela desde el primer interludio y se prolonga en los restantes:

¿Por qué nadie me busca?

¿Por qué nadie me encuentra?

¿Quién me trajo a este lugar de tinieblas?

¿Qué castigo es?

¿A quién protegí? ¿A quién cuidé?

¿A quién amé?

¿Quién me trajo a este lugar de tinieblas?

Memoria, memoria, casa de pena

Nadie quiere habitarla

Y allí me dejan.

Memoria, memoria, casa de pena.

¿Quién me trajo a este lugar de tinieblas? (Interludio 2)

En el quinto Interludio, junto con el reiterado motivo inicial, aparece la figura de Juan que se ha convertido en el testigo de lo sucedido y, como tal, en la memoria que se ha reclamado:

¿Por qué nadie me busca?

¿Por qué nadie me encuentra?

Juan ha vuelto 
De la muerte me sacó

No es la muerte lo que pesa

Es la forma de morir

De la muerte me sacó.

Dolorosamente Juan ha precariamente rescatado a Teresa por obra de la memoria recordando lo que realmente pesa, la forma de morir.

Un análisis del texto de La Casa sin sosiego resulta inevitablemente incompleto por dos importantes razones. La primera es la que atañe a toda obra dramática que se realiza en la representación, en la que el texto es el apoyo de una puesta en escena que le da razón de ser. La segunda, particular de este caso, es que se trata de una ópera de cámara, por lo que debería atenderse la música, con su especial caudal semántico, como elemento constitutivo de la representación. Es destacable, también, el hecho de que se trata de un texto literario que se musicaliza en forma de ópera de cámara. La obra se inscribe entre las pocas concebidas musicalmente. El libretista de una ópera es, generalmente, un escritor de segundo plano, poco recordado en relación con el autor de la música. En la historia de la ópera es frecuente encontrar obras teatrales adaptadas y musicalizadas, y aquí cabe incluir una gran cantidad de obras de Shakespeare y de la literatura grecolatina. En La casa sin sosiego asistimos al infrecuente caso de la obra de una consagrada dramaturga, con elevada calidad literaria, que se realiza en una síntesis indisociable de canto y música.

Se puede percibir, en la lectura de la obra, el clima de angustia y desolación en el que se mueven los personajes, pero al volverse canto la representación desborda el campo intelectual y emocional para penetrar y conmover otras profundidades humanas. Para Gambaro, el tema de la obra así lo imponía. 


\section{Biblografía}

Barthes, R. (1993), El placer del texto. Buenos Aires: Siglo XXI.

Bernabé, A., Casadesús, F. (2009), Orfeo y la tradición órfica. Un reencuentro. Madrid: Akal.

Bottini, A. (1992), Archeologia della salvezza. L’escatologia greca nelle testimonianze archeologiche. Milano: Longanesi.

Burkert, W. (1975), "Le laminette auree: da Orfeo a Lampone", in Orfismo in Magna Grecia. Napoli, Arte Tipografica: 81-104.

Cabañas, P. (1948), El mito de Orfeo en la Literatura Española. Madrid: Instituto Miguel de Cervantes de Filologia Hispanica (CSIC).

Calame, C. (1995), "Invocations et commentaires 'orphiques': transpositions funéraires de discours religieux", in Geny, E., Mactoux, M. M. (eds.), Discours religieux dans l'Antiquité. Besançon-Paris: 11-30. Actes du colloque de Besançon, 27-28 janvier 1995 Annales littéraires de l'Université de Besançon, Vol. 578, 1.

Cole, S. G. (1980), "New Evidence for the Mysteries of Dionysos", GRBS 21: 223-238.

Edmonds, R. (2004), Myths of the Underworld Journey. Plato, Aristophanes, and the 'Orphic' Gold Tablets. Cambridge: Cambridge University Press.

Curtius, E. R. (1955), Literatura europea y Edad Media latina. México: F. C. E.

Dubatti, J. (1989), "Griselda Gambaro: absurdo y sociedad en El desatino», Espacio de Crítica e Investigación Teatral 5: 87-93.

Dubatti, J. (1995), «Dramaturgia rioplatense en la dictadura. Poéticas del escamoteo y pacto de recepción política», in Spiller, R. (ed.), Culturas del Rio de la Plata (1973-1995). Frankfurt/Madrid, Vervuert: 517-529.

Eliade, M. (1999), Historia de las creencias y las ideas religiosas. Barcelona: Paidós Orientalia.

Giangrande, G. (1995), "Las dos fuentes en las laminillas órficas”, Minerva 9: 53-56.

González Delgado, R. (2008), Orfeo y Eurídice en la antigüedad. Mito y Literatura. Madrid: Ediciones clásicas.

Grimal, P. (1989), Diccionario de mitología griega y romana. Barcelona: Paidós.

Konig, I. (2002), Parodia y transculturación en el teatro de Gambaro. Universidad de Chile, s/f.

Laurence, A. (2008), «La casa sin sosiego de Griselda Gambaro: la resemantización del mito de Orfeo». La revista del CCC [en línea]. Septiembre / Diciembre $2008, n^{\circ} 4$. 
Merkelbach, R. (1999), "Die goldenen Totenpässe: ägyptisch, orphisch, bakchisch", ZPE 128: 1-13.

Riedweg, Ch. (1996), "Poesis Orphica et Bacchicus ritus: observationes quaedam ad lamellas aureas spectantes”, VoxLat 32: 475-489.

Salzman, P., Tola, E. (1995), "El camino órfico en la literatura argentina: La casa sin sosiego de Griselda Gambaro", in I Jornada Internacional de Literatura Argentina/Comparatistica. Buenos Aires, Facultad de Filosofía y LetrasUBA: 225-333.

Sternfeld, F. W. (1986), "The Orpheus myth and the libretto of Orfeo", in Whenham, J. (ed.), Claudio Monteverdi: Orfeo. Cambridge, Cambridge University Press: 20-45.

Tarantuviez, S. (2007), La escena del poder. El teatro de Griselda Gambaro. Buenos Aires: Corregidor.

Tortorelli Ghidini, M. (1995), "Dioniso e Persefone nelle lamine d'oro di Pelinna", Mathesis e Philia. Studi in onore di Marcello Gigante. Napoli, Revue des Études Anciennes 99. 1-2, 1997: 79-85. 